\title{
To e-smoke or not to e-smoke: is that a question?
}

\author{
Nino Künzli
}

Received: 5 August 2014/Accepted: 11 August 2014/Published online: 7 September 2014

(C) Swiss School of Public Health 2014

The use and regulation of e-cigarettes is hotly debated and the World Health Organization WHO, as the global authority for public health, has come under pressure from both pro-e-cigarette as well as contra-e-cigarette advocates, ${ }^{1,2}$ In contrast to the traditional tobacco debate with the public health research community arguing on one, and the tobacco industry and its constituencies on the other side, the current stage of the e-cigarette debate finds honest and independent public health scientists on both sides. Although it is obvious which one the tobacco and e-cigarette industries applaud (see Footnote 1), the more interesting question is why the public health community does not yet speak with "one voice". In this issue, IJPH has invited two commentaries-both written by independent public health scientists-to express their current views (Flahault and Etter 2014; McKee 2014). Flahault and Etter were among the 53 signatories of the "pro" letter (see Footnote 1) sent to WHO whereas McKee was among the 129 signatories of the "contra" letter (see Footnote 2) sent in reaction to the first one.

One major reason to still find public health professionals on both sides of the debate relates to the fact that the current state of knowledge about the pros and cons of e-cigarettes is not overwhelming; thus, many questions

This Editorial is one of three contributions in issue 5 (2014) on electronic cigarettes. The other contributions are available at doi:10.1007/s00038-014-0589-z, 10.1007/s00038-014-0597-z.

N. Künzli $(\bowtie)$

Swiss Tropical and Public Health Institute (SwissTPH),

Socinstrasse 57, P.O. Box 4002, Basel, Switzerland

e-mail: nino.kuenzli@unibas.ch

N. Künzli

University Basel, Basel, Switzerland remain unanswered, as also addressed in position papers of independent scientific authorities such as the recent statement of the Forum of International Respiratory Societies (Schraufnagel et al. 2014). The gaps of knowledge leave room for different views and priorities. The readers are invited to critically think about those views, as expressed in the two commentaries.

It is now the task of the scientific community to fill the gaps with independent research. At this stage, those prioritizing the perspective of people who (still) smoke cigarettes come to partly different conclusions than those emphasizing the population at large. Research should investigate how to shape e-cigarette policies to maximize the overall public health benefits. Whether the answer will be a global one-such as for cigarettes-or differ across the globe needs to be addressed. For example, regions like California where tobacco smoking prevalence has reached a historic low-according to 2012 CDC surveys, less than $13 \%$ of adult Californians smoke-may come to different conclusions for e-cigarettes than countries such as Chinawhere more than half of all men are smokers - and other emerging and developing economies where the tobacco industry successfully perpetuates its grossly unethical strategy to make as many people as possible addicted to nicotine.

Scientists currently at the "pro-side" face a particular challenge, namely, how to remain independent of the industry's interests. "Big tobacco" and the partly independent e-cigarette industry will warmly welcome

\footnotetext{
${ }^{1}$ http://nicotinepolicy.net/documents/letters/MargaretChan.pdf. Accessed 1 Aug 2014.

2 https://tobacco.ucsf.edu/129-public-health-and-medical-authorities31-countries-write-who-dg-chan-urging-evidence-based-appro. Accessed 1 Aug 2014.
} 
"academic experts" expressing views that coincidethough for different arguments-with their vested interest. It will be essential that evidence about the pros and cons of e-cigarettes will be provided from independently funded research. The scientific community should adhere to the same ethical standards and disclosure practices common for independent research in the field of tobacco and health. This should include transparency about funders not only of research but also of conferences, such as the 2014 Global Forum on Nicotine (http://gfn.net.co/) where signatories of the "pro-letter" presented. The public has also the right to know the funding sources of media campaigns such as the one accompanying the "pro"-letter sent to WHO, which generated, according to the web site of a co-signing consultant, the "biggest ever global media coverage on e-cigarettes". 3

Scientist should also condemn (and certainly abstain from) aggressive attacks in social media on those expressing different views. Social media now provide platforms to easily spread vile aggressions and attacks against science and scientists to promote believes and personal interests rather than knowledge. Indeed, the author of our invited "contra"-commentary became subject of massive villain personal attacks from the e-cigarette community after he expressed his "contra"-view. ${ }^{4}$
The impact of this new phenomenon on scientists reminds us about the impact of the very old strategy of "big tobacco" to fabricate "doubts" and "debates": it results inevitably in a frustrating time consuming distraction of the research community. There is little doubt that the industry knows how to manipulate social media to orchestrate their vested interests. However, what we need from the independent scientific community are neither blogs nor tweets or facebook discussions and reactions but independent peer reviewed research to foster a science-based e-cigarette policy framework. IJPH welcomes original articles from new studies investigating the public health dimensions of e-cigarettes.

\section{References}

Flahault A, Etter J-F (2014) Electronic cigarettes: it is urgent to promote them to save lives! Int J Public Health. doi:10.1007/ s00038-014-0597-z

McKee M (2014) Electronic cigarettes: proceed with great caution. Int J Public Health. doi:10.1007/s00038-014-0589-z

Schraufnagel DE, Blasi F, Drummond MB et al (2014) Electronic cigarettes: a position statement of the forum of international respiratory societies. Am J Respir Crit Care Med. doi:10.1164/ rccm.201407-1198PP

\footnotetext{
${ }^{3} \mathrm{http} / / /$ nicotinepolicy.net/n-s-p/1853-letter-from-53-scientists-towho-dg. Accessed 1 Aug 2014.

${ }^{4}$ http://www.dailymail.co.uk/news/article-2656160/Health-campaigners-receiving-incredibly-abusive-emails-bitter-row-alternative-smoking. html\#ixzz398Kp7n6B. Accessed 1 Aug 2014.
} 